\title{
Cardiothoracic
}

Transplantation

\section{Prognosis of patients removed from a transplant waiting list for medical improvement: Implications for organ allocation and transplantation for status 2 patients}

\author{
Katherine J. Hoercher, RN, ${ }^{a}, c, d$ Edward R. Nowicki, MD, MS, ${ }^{a}$ Eugene H. Blackstone, MD, ${ }^{a, b, *}$ Gurmeet Singh, MD, ${ }^{a}$ \\ Joan M. Alster, MS, ${ }^{b}$ Gonzalo V. Gonzalez-Stawinski, MD, ${ }^{\text {a,d }}$ Randall C. Starling, MD, MPH, ${ }^{c, d}$ James B. Young, MD, ${ }^{c, d}$ \\ and Nicholas G. Smedira, MD ${ }^{\mathrm{a}, \mathrm{d}}$
}

From the Departments of Thoracic and Cardiovascular Surgery, ${ }^{\text {a }}$ Quantitative Health Sciences, ${ }^{\mathrm{b}}$ Cardiovascular Medicine, ${ }^{\mathrm{c}}$ and the Kaufman Center for Heart Failure, ${ }^{d}$ Cleveland Clinic, Cleveland, Ohio.

Read at the Thirty-third Annual Meeting of the Western Thoracic Surgical Association, Santa Ana Pueblo, NM, June 27-30, 2007.

* Supported in part by the Kenneth Gee and Paula Shaw, PhD, Chair in Heart Research.

Randall C. Starling reports consulting fees from Medtronic, James B. Young reports consulting fees from Guidant and Medtronic and grant support from Medtronic.

Received for publication Nov 13, 2007; accepted for publication Jan 25, 2008.

Address for reprints: Katherine J. Hoercher, RN, Kaufman Center for Heart Failure, Cleveland Clinic, 9500 Euclid Ave/JJ-40, Cleveland, OH 44195 (E-mail: hoerchk@ ccf.org).

J Thorac Cardiovasc Surg 2008;135:115966

0022-5223/\$34.00

Copyright (C) 2008 by The American Association for Thoracic Surgery

doi:10.1016/j.jtcvs.2008.01.017
Objectives: To address the present controversy regarding optimal management of status 2 heart transplant candidates, we studied the short- and long-term fate of medically improved patients removed from our transplant waiting list to assess return of heart failure and occurrence of sudden cardiac death, identify interventions to improve outcomes, and compare their survival with that of similar transplanted patients.

Methods: From January 1985 to February 2004, 100 status 2 patients were delisted for medical improvement (median on-list duration, 314 days). Return of heart failure, sudden cardiac death, and all-cause mortality were determined from follow-up (mean, $7.7 \pm 3.9$ years among survivors; $10 \%$ followed $>12$ years). Hazard function modeling, competing-risks analyses, simulation, and propensity matching to equivalent patients undergoing transplantation were used to analyze and compare outcomes and predict benefit of interventions.

Results: Freedom from return of heart failure was $77 \%$ at 5 years. The most common mode of death was sudden cardiac death, with risk peaking at 2.5 years after delisting but remaining at $3.5 \%$ per year thereafter. Event-free survival at 1,5 , and 10 years was $94 \%, 55 \%$, and $28 \%$, respectively; simulation demonstrated that implantable cardioverter-defibrillators could have improved this to $45 \%$ at 10 years. Overall survival after delisting was better than that of matched status 2 patients who underwent transplantation, but was demonstrably worse after 30 months.

Conclusions: Status 2 patients, including those delisted, require vigilant surveillance and optimal medical management, implantable cardioverter-defibrillators, and a revised approach to transplantation timing, such that overall salvage is maximized while allocation of scarce organs is optimized.

$\mathrm{C}$ ardiac transplantation has long been thought to be the most appropriate therapeutic option for patients with end-stage heart failure, but with the proliferation of life-extending alternative medical and surgical therapies of the past decade, this thinking might no longer be valid. Indeed, an increasing body of observational evidence casts doubt on a clear benefit of cardiac transplantation for Unified Network for Organ Sharing (UNOS) status 2 outpatients receiving optimal medical therapy. ${ }^{1,2}$ To date, however, these reports are limited by short-term follow-up. Although a randomized trial of transplantation versus medical therapy for such patients has been proposed, it is unlikely to be undertaken. ${ }^{3,4}$ 


\section{Abbreviations and Acronyms}

ICD = implantable cardioverter-defibrillator

NYHA $=$ New York Heart Association

SCD = sudden cardiac death

UNOS = Unified Network for Organ Sharing

$\dot{\mathrm{VO}}_{2}=$ peak oxygen consumption

In the absence of such a trial, we sought to augment shortterm data with long-term information by studying the fate of status 2 patients removed over the years from our heart transplant waiting list (delisted) because of medical improvement. We considered such patients as surrogates for medical therapy versus transplantation in stable outpatients with chronic heart failure. Specifically assessed were return of heart failure and occurrence of sudden cardiac death (SCD), interventions to improve outcomes, and survival compared with that of status 2 patients undergoing transplantation.

\section{Materials and Methods Patients}

From January 1, 1985, to February 1, 2004, 229 patients were removed (delisted) from Cleveland Clinic's cardiac transplant waiting list for alternative nontransplantation operations $(n=70)$, psychosocial factors $(\mathrm{n}=30)$, medical contraindications to transplantation $(\mathrm{n}=29)$, and medical improvement $(\mathrm{n}=100)$. This last group of 100 patients, all of whom were in UNOS status 2 at delisting, formed the study cohort. Patients transferred to other cardiac transplant programs were not considered delisted.

Cases were identified through the Cleveland Clinic Unified Transplant Database, which is used for UNOS reporting and has been approved for use in research by the institutional review board, with patient consent waived. These data were confirmed and supplemented by review of each patient's clinical records to determine the reason for delisting, time on the waiting list, UNOS status and New York Heart Association (NYHA) functional class at delisting, and, when available, peak oxygen consumption $\left(\dot{\mathrm{V}}_{2}\right)$ during exercise at listing and delisting.

Clinical characteristics of patients at listing and delisting are presented in Table 1. Of this group, $91 \%$ were aggressively treated with optimal medical therapy for a minimum of 9 months before listing. Despite optimal medical therapy, persistent NYHA class III or IV symptoms and $\dot{\mathrm{VO}}_{2}$ of less than $14 \mathrm{~mL} \cdot \mathrm{kg}^{-1} \cdot \mathrm{min}^{-1}$ guided the decision to list potential transplant candidates. The remaining patients were admitted with cardiogenic shock requiring mechanical circulatory support and listed for transplantation within a week of referral.

Substantial subjective clinical improvement in NYHA class occurred in $86 \%$ of delisted patients, and there was an objective improvement in mean $\dot{\mathrm{VO}}_{2}$ from $14 \pm 3.3$ to $19 \pm 3.2 \mathrm{~mL} \cdot \mathrm{kg}^{-1}$. $\min ^{-1}$ at delisting. Mean age at delisting was $52 \pm 11$ years (range, 26-73 years with 9\% >age 65 years); $82 \%$ were men (Table 1 ). Median time on the waiting list was 314 days. Diagnoses were about equally divided between dilated and ischemic cardiomyopathy. Of note, malignant ventricular dysrhythmias were a common occurrence while these patients were on the waiting list.
TABLE 1. Characteristics of patients delisted for medical improvement $(\mathbf{n}=\mathbf{1 0 0})$

\begin{tabular}{|c|c|}
\hline Characteristic & No. \\
\hline Male sex & 82 \\
\hline \multicolumn{2}{|l|}{ Cardiomyopathy } \\
\hline Dilated & 48 \\
\hline Ischemic & 45 \\
\hline Valvar & 5 \\
\hline Myocarditis & 2 \\
\hline \multicolumn{2}{|l|}{ UNOS status at listing } \\
\hline 1 & 20 \\
\hline 2 & 80 \\
\hline \multicolumn{2}{|l|}{ NYHA class at listing } \\
\hline II & 9 \\
\hline III & 60 \\
\hline IV & 22 \\
\hline Uncertain & 9 \\
\hline Peak $\dot{\mathrm{VO}}_{2}$ at listing (mean $\pm \mathrm{SD}, \mathrm{n}=34$ ) & $13.7 \pm 3.3$ \\
\hline Atrial fibrillation or flutter during listing & 41 \\
\hline \multicolumn{2}{|l|}{ Ventricular dysrhythmias during listing } \\
\hline Sudden cardiac death & 14 \\
\hline Ventricular fibrillation & 4 \\
\hline Ventricular tachycardia & 48 \\
\hline Complete heart block & 3 \\
\hline Mechanical circulatory support during listing & 9 \\
\hline Age at delisting (y; mean $\pm S D)$ & $52 \pm 11$ \\
\hline$<50$ & 36 \\
\hline $50-65$ & 55 \\
\hline$\geq 65$ & 9 \\
\hline $\begin{array}{l}\text { Time on waiting list (d; median [15th-85th } \\
\text { percentiles]) }\end{array}$ & $314(96-831)$ \\
\hline \multicolumn{2}{|l|}{ NYHA class at delisting } \\
\hline I & 13 \\
\hline II & 73 \\
\hline III & 1 \\
\hline Not available & 13 \\
\hline Peak $\dot{\mathrm{VO}}_{2}$ at delisting (mean $\pm \mathrm{SD}, \mathrm{n}=22$ ) & $19.4 \pm 3.2$ \\
\hline
\end{tabular}

UNOS, Unified Network for Organ Sharing; NYHA, New York Heart Association; $\dot{\mathrm{VO}}_{2}$, peak oxygen consumption; $S D$, standard deviation.

\section{Definitions and Indications}

Medically improved patients were those who were in UNOS status 2 for more than 6 months with objective improvement in NYHA class (all but 1 known to be in NYHA class I or II at delisting, Table 1). Indications for delisting were improved $\mathrm{V}_{2}$ during exercise from listing to delisting, subjective improvement in heart failure symptoms, and a heart failure team consensus that cardiac transplantation would not provide a survival benefit over medical management. No formal surveillance program was implemented; rather, patients were remanded to the care of their local health care providers.

\section{Outcomes}

Patients or their surviving families were followed cross-sectionally by using an institutional review board-approved telephone script, with a common closing date of September 15, 2005. Follow-up 
was $100 \%$ complete, with mean follow-up of $7.7 \pm 3.9$ years among survivors; $10 \%$ were followed more than 12 years. Outcomes elicited included (1) return of heart failure, defined as return of NYHA class IV heart failure symptoms, relisting for transplantation, institution of mechanical circulatory support, or reported death in heart failure; (2) mode of death (heart failure, SCD, or noncardiac death); (3) insertion of an implantable cardioverter-defibrillator (ICD) among the 99 patients not having such a device inserted before delisting; and (4) all-cause mortality at any time during follow-up.

\section{Data Analysis}

All time-related post-delisting events were analyzed nonparametrically by using the method of Kaplan and Meier and parametrically by multiphase hazard modeling. ${ }^{5}$ (For additional details, see http://www.clevelandclinic.org/heartcenter/hazard.) Multivariable analysis of outcomes was performed in the hazard function domain by using bagging as the primary variable selection method. ${ }^{6,7}$ For this, 1000 bootstrap data sets were analyzed with a selection criterion of $P=.05$, followed by aggregation of models by the median rule. Variables used in these analyses were age at delisting (and its potential linearizing transformations of scale), sex, race, indication for listing (ischemic vs dilated cardiomyopathy vs other), dysrhythmia during listing (atrial fibrillation or flutter, sustained ventricular tachycardia, and SCD), NYHA class at listing and delisting, UNOS status at listing, time on the waiting list, and date of delisting, expressed as the interval between 1985 and delisting.

Event-free survival was defined as freedom from 3 end states: return of heart failure, SCD, and all other modes of death, each censored at any subsequent transplantation. Nonparametric simultaneous estimation of cumulative incidence for these events used the multiple decrement method of Andersen and colleagues. ${ }^{8}$ For parametric estimation, rate of transition (hazard function) from event-free survival to each end state was estimated, and event-free survival and cumulative incidence of end states were calculated by using numeric integration. To estimate the potential benefit of ICD insertion, we simulated event-free survival were SCD completely eliminated.

Survival after delisting for medical improvement was compared with survival after transplantation for similar patients. For this, patients who underwent transplantation as UNOS status 2 were matched with delisted patients on age, sex, race, UNOS status at listing, diagnosis at listing, transplantation date, and waiting time to transplantation or delisting by using propensity score methodology. ${ }^{7,9}$ This yielded 85 matched pairs.

\section{Results}

\section{Temporal Changes in Heart Failure Severity}

During follow-up, 30 of 100 patients delisted for medical improvement had return of heart failure. Of these, only 8 were relisted (5 subsequently transplanted), and 15 died of heart failure. Six others had medical contraindications to transplantation, and importantly, the remaining patients were not referred back to a transplantation center to be reevaluated for transplantation as their heart failure worsened.

Risk of return of heart failure increased rapidly to $3.5 \%$ per year and then rose more slowly thereafter-but never leveled off or decreased-such that by 5 years it was nearly dou-

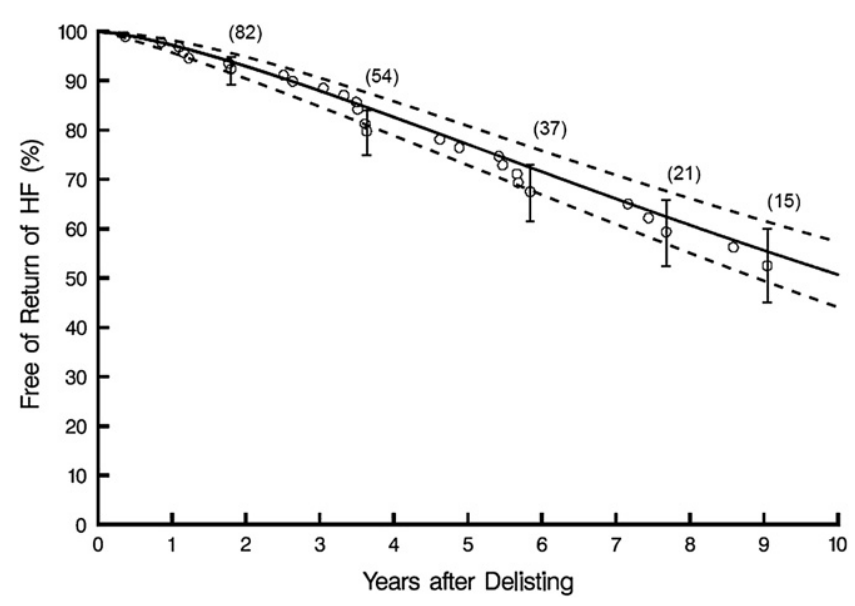

Figure 1. Freedom from return of heart failure $(H F$, return to New York Heart Association Class IV, relisting for transplantation, implementation of mechanical circulatory support, or death from heart failure). Each symbol represents a death positioned actuarially, vertical bars are $68 \%$ confidence limits, and numbers in parentheses are patients remaining at risk. The solid line is the parametric estimate enclosed within dashed $68 \%$ confidence limits.

ble that at 1 year (7.2\% per year). This resulted in freedom from return of heart failure at 1, 5, and 10 years of $97 \%$, $77 \%$, and $51 \%$, respectively (Figure 1). The only incremental risk factor for return of heart failure was older age at delisting (Table 2).

\section{Sudden Cardiac Death}

SCD was the most common mode of death, occurring in 26 patients. Risk of SCD peaked about 2.5 years after delisting at $10 \%$ per year and then decreased to a constant rate of $3.5 \%$ per year (Figure 2). As a result, freedom from SCD at 1, 5, and 10 years was $96.5 \%, 75 \%$, and $62 \%$, respectively. Incremental risk factors for SCD were ischemic cardiomyopathy

TABLE 2. Incremental risk factors for events after delisting for medical improvement

\begin{tabular}{|c|c|c|}
\hline Event and risk factors & Coefficient \pm SE & $P$ value \\
\hline \multicolumn{3}{|l|}{ Return of heart failure } \\
\hline Older age at delisting* & $1.47 \pm 0.48$ & .002 \\
\hline \multicolumn{3}{|l|}{ Sudden cardiac death } \\
\hline Ischemic cardiomyopathy & $1.49 \pm 0.63$ & .02 \\
\hline Earlier in experience $\dagger$ & $-0.33 \pm 0.098$ & .0006 \\
\hline \multicolumn{3}{|l|}{ All-cause mortality } \\
\hline Older age at delisting* & $1.18 \pm 0.36$ & .001 \\
\hline Longer time on waiting list & $0.31 \pm 0.13$ & .02 \\
\hline Earlier in experience $\ddagger$ & $-1.00 \pm 0.25$ & $<.0001$ \\
\hline
\end{tabular}

$S E$, Standard error. ${ }^{*}(\text { Age } / 50)^{2}$, squared transformation. †Years to delisting since 1985. $\ddagger$ Ln(years to delisting since 1985), logarithmic transformation. 


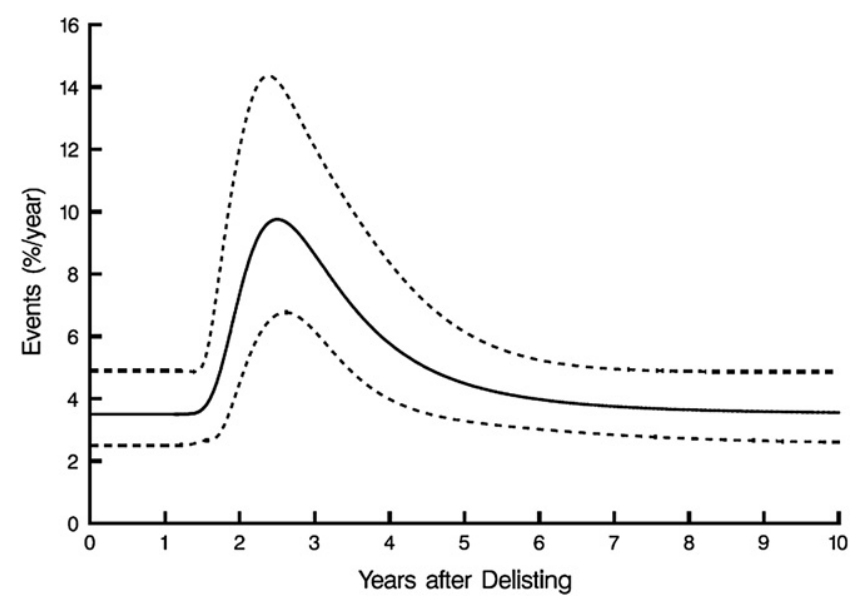

Figure 2. Risk of sudden death after delisting among patients without an implantable cardioverter-defibrillator. Dashed lines represent $68 \%$ confidence limits.

(hazard ratio, 4.5) and delisting early in the experience (Table 2). ICD insertion was not the standard of care for much of the study time frame; thus, at delisting, only 1 patient had an ICD, but during the course of patient follow-up, 18 underwent ICD implantation.

\section{Event-free Survival}

Risk of death in noncardiac modes increased moderately up to 3 to 4 years and then slowly decreased (Figure $3, A$ ). If one then combines the competing risks of return of heart failure, SCD, and noncardiac death, event-free survival at 1, 5, and 10 years after delisting was $94 \%, 55 \%$, and $28 \%$, respectively (Figure 3, B). If one assumes $100 \%$ effectiveness of ICDs in preventing SCD, we estimated by means of simulation that event-free survival would have been $97 \%, 73 \%$, and $45 \%$, respectively (Figure 4 ).

\section{Survival and Comparison With Transplantation}

During follow-up, 58 patients died. Survival of patients at 1 , 5 , and 10 years was $93 \%, 63 \%$, and $35 \%$, respectively, with a median time to death of 7 years (Figure 5). Incremental risk factors for death included older age at delisting, longer duration on the waiting list, and delisting earlier in the experience (particularly within the first 5 years). Among 85 propensitymatched pairs, survival was better for about 18 months for delisted patients than for those undergoing transplantation in status 2 because of the high early risk of transplantation (Figure 6). After about 30 months, survival was demonstrably better after transplantation (confidence limits nonoverlapping). Thus, at 5 and 10 years, survival after transplantation of status 2 patients was $85 \%$ and $70 \%$, respectively, compared with $63 \%$ and $36 \%$, respectively, for matched delisted status 2 patients.
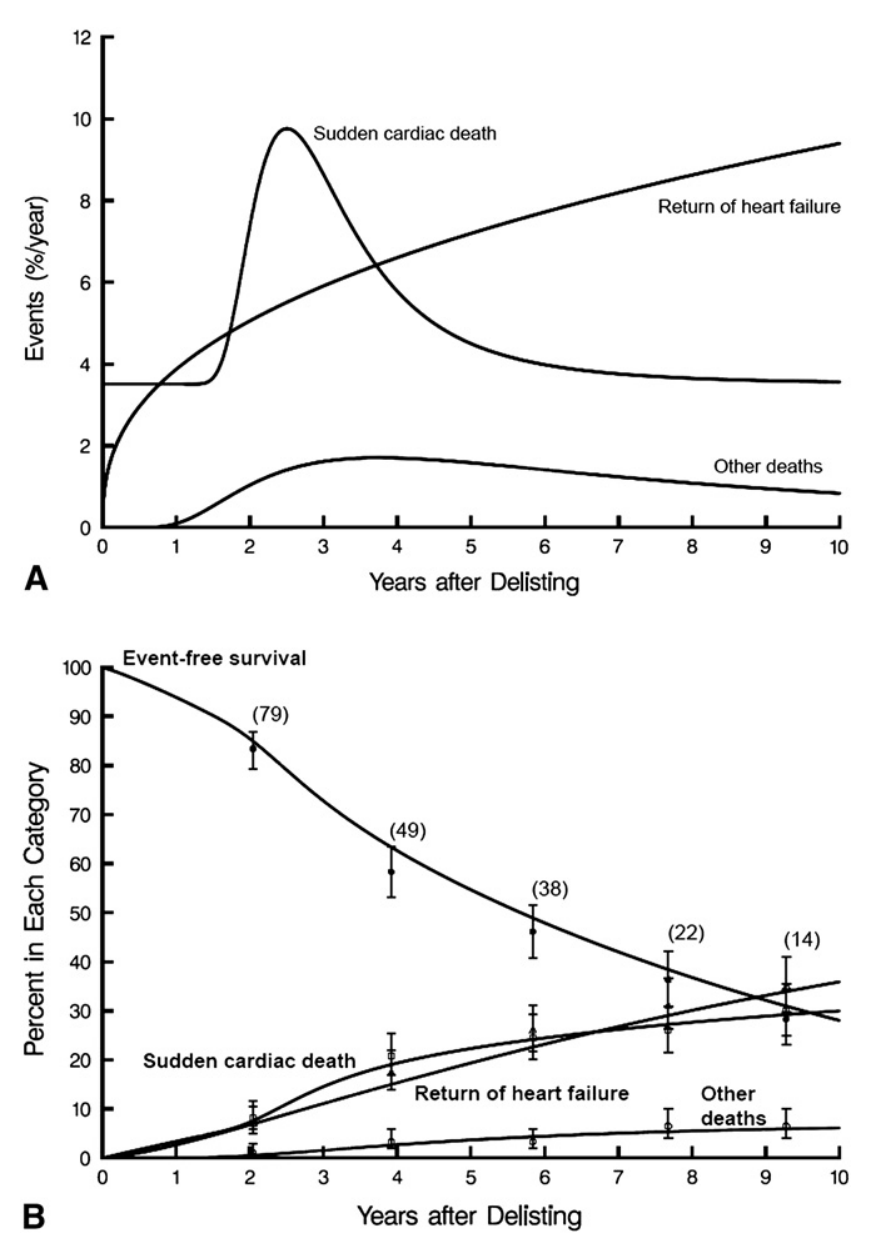

Figure 3. Competing risks after delisting for medical improvement. A, Rates of transition from event-free survival to heart failure, sudden cardiac death, or death from other causes. B, Resulting proportion of patients in each state (event-free survival, heart failure, sudden cardiac death, or other modes of death) across follow-up.

\section{Discussion}

\section{Principal Findings}

Approximately one third of patients removed from the heart transplant waiting list for medical improvement experienced return of heart failure, most dying without transplantation, but SCD was the leading cause of death. Short-term survival was better than that for patients undergoing transplantation (up to 18 months), but in the long-term, return of heart failure symptoms, SCD, and death from heart failure began exacting a heavy toll. After delisting, systematic follow-up with a heart failure specialist and ICD insertion might have substantially improved outcomes.

\section{Temporal Changes in Heart Failure Severity}

An increase in peak $\dot{\mathrm{VO}}_{2}$ levels that occurred during listing, which might have been due to the intensity of therapy in such 


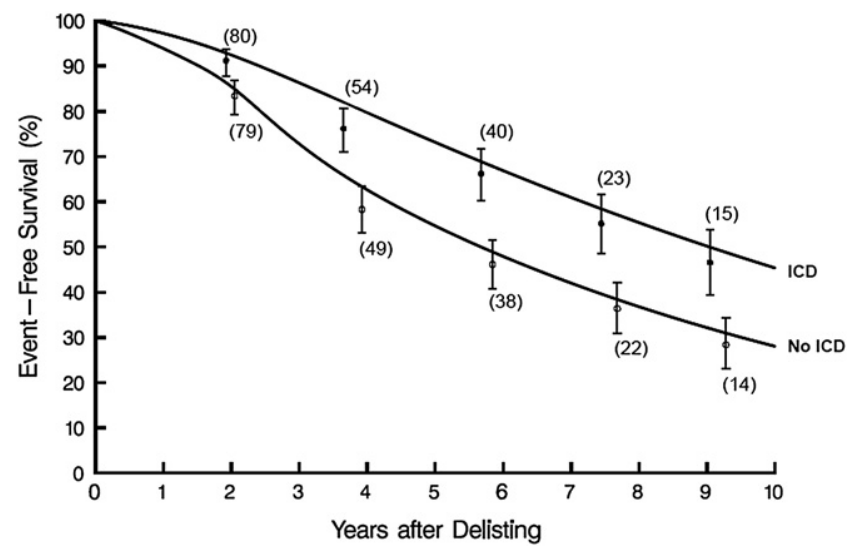

Figure 4. Simulated improvement in event-free survival of patients were sudden cardiac death to be eliminated by inserting implantable cardioverter-defibrillators (ICD). Parametric survival curves are formatted as for Figure 1, except parametric confidence limits are not shown.

patients, conferred only a short-term benefit but was not predictive of late outcomes. Favorable short-term outcomes $(<2$ years) in listed patients who increased their $\mathrm{V}_{2}$ levels has also been reported in some, ${ }^{10,11}$ but not all, ${ }^{12}$ series. The 9 patients listed for cardiogenic shock and requiring temporary mechanical circulatory support all had dramatic return of cardiac function and were subsequently delisted.

Risk of return of heart failure symptoms increased rapidly within a year of delisting and then slowly but steadily continued to increase. Late return of heart failure symptoms is not surprising because heart failure is a chronic and progressive disease. Importantly, follow-up care, especially with regard to contemporary disease management, was neither systematic nor intensive. Only $5 \%$ of patients were followed by a heart failure specialist after delisting; thus, the levels of

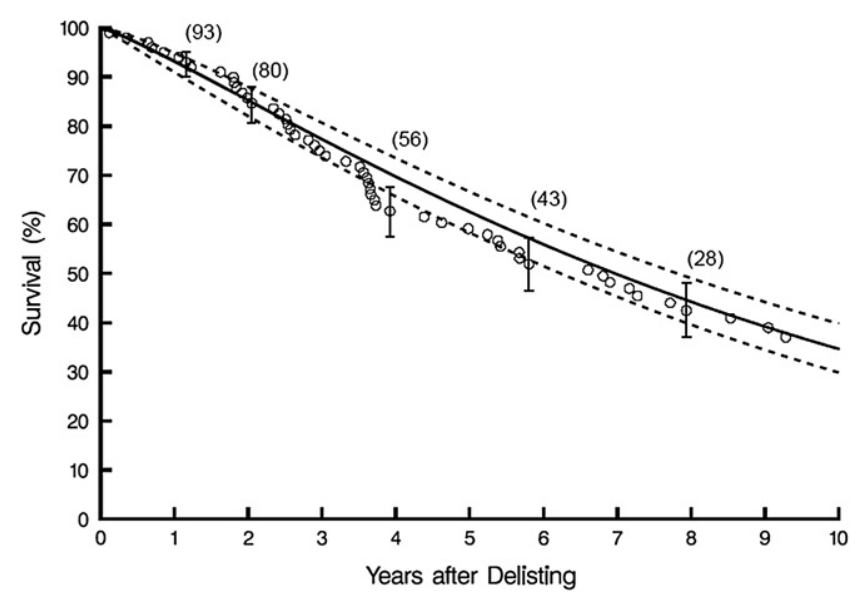

Figure 5. Survival of medically improved patients after delisting. Format is as in Figure 1.

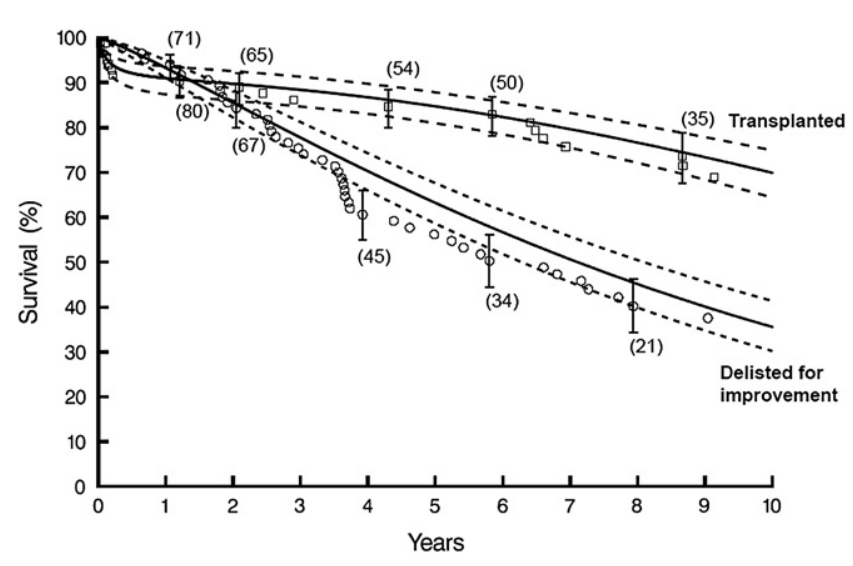

Figure 6. Comparison of survival of medically improved patients after delisting (circles) to propensity-matched Unified Network for Organ Sharing status 2 patients after cardiac transplantation (squares). Format is as in Figure 1.

care and compliance with heart failure therapies were unknown, and critically, the majority of patients who returned to NYHA class IV heart failure were not referred back to our transplantation center. Previous studies, as well as recent data, suggest that outcomes are improved by the attentive care provided within a heart failure disease management program. $^{13-15}$

\section{Sudden Cardiac Death}

SCD was the most common mode of death for these patients, accounting for $45 \%$ of deaths. By means of simulation, we estimated that an ICD would have substantially improved intermediate and long-term event-free survival in this population after delisting because it clearly affects a mechanism of death not captured by improved functional capacity or exercise tolerance. Results of this simulation are similar to those observed in the Multicenter Automatic Defibrillator Implantation Trial II study of ICD therapy in patients with prior myocardial infarction and reduced left ventricular function, as well as in clinical studies of stable heart transplant candidates. ${ }^{16-18}$ Beyond optimal medical therapy, the Sudden Cardiac Death in Heart Failure Trial demonstrated a $46 \%$ relative reduction in the risk of SCD in NYHA class II patients with an ICD and further explains the high risk of SCD in our stable heart failure group, patients who, for the most part, did not have an ICD. ${ }^{19}$

In a recent analysis of 50,000 UNOS registrants awaiting heart transplantation between 1990 and 2005, the presence of an ICD in status 1 candidates on the day of listing correlated with improved outcomes. ${ }^{20}$ This same study demonstrated that 1-year survival of non-transplanted status 2 candidates in the most recent era (2000-2005) is approaching that of survival after transplantation. Although the authors were unable 
to determine the specific reasons for these improved outcomes, it is important to note that in the most recent era, $47 \%$ of listed status 2 patients had an ICD compared with $18 \%$ between 1995 and 1999 and 0\% between 1990 and 1994.

Although the results of the Multicenter Automatic Defibrillator Implantation Trial II and Sudden Cardiac Death in Heart Failure Trial in NYHA class II patients are well known, and furthermore, ICD implantation is a class IA recommendation from the 2006 American College of Cardiology/ American Heart Association/European Society of Cardiology guidelines, ${ }^{21}$ Lietz and Miller ${ }^{20}$ have shown that even in the most recent era, fewer than half of status 2 patients on the UNOS waiting list had ICDs. The ominous findings of SCD in our own study clearly demonstrate the need for ICDs in these "low-risk" patients.

\section{Survival}

Recent studies question whether cardiac transplantation provides a survival benefit over optimal medical therapy in status 2 patients. ${ }^{1,2}$ To date, all published survival data comparing medical management of transplant candidates with transplanted patients are limited by follow-up of only 1 to 5 years. ${ }^{10,11,22,23}$ The strength of our investigation is the 10year follow-up. If one assumes that our delisted patients were the healthiest or lowest-risk patients, their survival should be better than that of the average status 2 patient after transplantation, and in our experience this is in fact the case out to at least 18 months. However, heart failure and SCD escalate thereafter, and data from both our study and prior investigations are insufficient to predict who will deteriorate over time.

\section{Limitations}

This is a nonrandomized observational study encompassing 20 years of experience from a single high-volume transplantation center but involving a relatively small number of patients. $\mathrm{Nu}-$ merous changes in clinical management occurred during this time, and multiple surgeons and cardiologists were involved in caring for these patients. Unfortunately, we were unable to quantify the intensity and quality of care after delisting to determine how these might have affected outcome. Major advances in medical and device therapies occurred as well, including use of $\beta$-blockers, ICDs, cardiac resynchronization therapy, and dissemination of evidence-based care. Importantly, because of improved survival in patients treated with $\beta$-blockers, the traditional cutoff point of less than $14 \mathrm{mg}$. $\mathrm{kg}^{-1} \cdot \mathrm{min}^{-1}$ for transplantation is being reassessed; a value of less than $12 \mathrm{mg} \cdot \mathrm{kg}^{-1} \cdot \mathrm{min}^{-1}$ might be more appropriate.

\section{Clinical Implications and Recommendations for Practice Guidelines}

Although the outcomes of this study cannot be extrapolated to all status 2 transplant candidates, and we do not believe it to be a direct substitute for a trial of tailored medical therapy versus transplantation, we believe our findings have several implications for both status 2 patients and those being considered for delisting.

First, all patients meeting guideline criteria should have an ICD implanted.

Second, follow-up must be intense and is best done by heart failure specialists as if patients remained on the transplant waiting list.

Third, close periodic surveillance (every 3-6 months) is required to identify patients whose cardiac function is deteriorating.

Fourth, additional methods for monitoring both listed and delisted patients should be investigated, including implantable hemodynamic devices, microvolt T-wave alternans, and biomarkers, to anticipate deterioration earlier and prompt renewed consideration for relisting or status upgrade.

Fifth, timing of transplantation in this population remains a dilemma. More detailed and longer-term investigation into the prediction of survival for status 2 patients is needed, as has already been done for status 1 patients. Reliable predictive models for status 2 patients might help discriminate low- from high-risk patients, helping to guide time of listing.

Sixth, UNOS modifications to the current allocation system might be required when accurate predictive models become available. If the number of patients listed continues to decrease and efforts to increase organ donation are successful, more status 2 patients might be offered organs. In that case, one would need to balance long-term survival of the graft and morbidity associated with long-term immunosuppression against good short-term survival of low-risk patients who do not undergo transplantation. Consequently, it might be that in this situation, the lowest-risk patients should have transplantation delayed as long as possible and undergo transplantation only when matched to a perfect heart.

We thank Lucy Thiuta, MS, for data management and analysis and Tess Parry for editorial assistance.

\section{References}

1. Jimenez J, Bennett Edwards L, Higgins R, Bauerlein J, Pham S, Mallon S. Should stable UNOS Status 2 patients be transplanted? $J$ Heart Lung Transplant. 2005;24:178-83.

2. Deng MC, De Meester JM, Smits JM, Heinecke J, Scheld HH. Effect of receiving a heart transplant: analysis of a national cohort entered on to a waiting list, stratified by heart failure severity. Comparative Outcome and Clinical Profiles in Transplantation (COCPIT) Study Group. BMJ. 2000;321:540-5.

3. Deng MC, Smits JM, Young JB. Proposition: the benefit of cardiac transplantation in stable outpatients with heart failure should be tested in a randomized trial. J Heart Lung Transplant. 2003;22:113-7.

4. Young JB. Heart failure's near dead and dying: reconsidering our heart transplant wait list scheme. J Am Coll Cardiol. 2007;50:1291-3.

5. Blackstone EH, Naftel DC, Turner ME Jr. The decomposition of timevarying hazard into phases, each incorporating a separate stream of concomitant information. J Am Stat Assoc. 1986;81:615-24.

6. Breiman L. Bagging predictors. Machine Learning. 1996;24:123-40.

7. Blackstone EH. Breaking down barriers: helpful breakthrough statistical methods you need to understand better. J Thorac Cardiovasc Surg. 2001;122:430-9. 
8. Andersen PK, Borgan O, Gill RD, Keiding N. Statistical models based on counting processes. New York: Springer Verlag; 1995.

9. Rosenbaum PR, Rubin DB. The central role of the propensity score in observational studies for causal effects. Biometrika. 1983;70:41-55.

10. Stevenson LW, Hamilton MA, Tillisch IH, Moriguchi JD, Kobashigawa JA, Creaser JA, et al. Decreasing survival benefit from cardiac transplantation for outpatients as the waiting list lengthens. J Am Coll Cardiol. 1991;18:919-25.

11. Levine TB, Levine AB, Goldberg AD, Tobes M, Narins B, Lesch M. Clinical status of patients removed from a transplant waiting list rivals that of transplant recipients at significant cost savings. Am Heart $J$. 1996;132:1189-94.

12. Gullestad L, Myers J, Ross H, Rickenbacher P, Slauson S, Bellin D, et al. Serial exercise testing and prognosis in selected patients considered for cardiac transplantation. Am Heart J. 1998;135:221-9.

13. Rich MW, Beckham V, Wittenberg C, Leven CL, Freedland KE, Carney RM. A multidisciplinary intervention to prevent the readmission of elderly patients with congestive heart failure. N Engl J Med. 1995; 333:1190-5.

14. Kasper EK, Gerstenblith G, Hefter G, Van Anden E, Brinker JA, Thiemann DR, et al. A randomized trial of the efficacy of multidisciplinary care in heart failure outpatients at high risk of hospital readmission. J Am Coll Cardiol. 2002;39:471-80.

15. Yancy CW, Krum H, Massie BM, Silver MA, Stevenson LW, Cheng M, et al. Follow-up serial infusions of nesiritide for advanced heart failure (FUSION II) trial. Circulation: Heart Failure. 2008; in press.

16. Moss AJ, Zareba W, Hall WJ, Klein H, Wilber DJ, Cannom DS, et al. Prophylactic implantation of a defibrillator in patients with myocardial infarction and reduced ejection fraction. $N$ Engl J Med. 2002;346: 877-83.

17. Sandner SE, Wieselthaler G, Zuckermann A, Taghavi S, Schmidinger H, Pacher R, et al. Survival benefit of the implantable cardioverter-defibrillator in patients on the waiting list for cardiac transplantation. Circulation. 2001;104:I171-6.

18. Saba S, Atiga WL, Barrington W, Ganz LI, Kormos RL, MacGowan GA, et al. Selected patients listed for cardiac transplantation may benefit from defibrillator implantation regardless of an established indication. J Heart Lung Transplant. 2003;22:411-8.

19. Bardy GH, Lee KL, Mark DB, Poole JE, Packer DL, Boineau R, et al. Amiodarone or an implantable cardioverter-defibrillator for congestive heart failure. N Engl J Med. 2005;352:225-37.

20. Lietz K, Miller LW. Improved survival of patients with end-stage heart failure listed for heart transplantation: analysis of organ procurement and transplantation network/U.S. United Network of Organ Sharing data, 1990-2005. J Am Coll Cardiol. 2007;50:1282-90.

21. Zipes DP, Camm AJ, Borggrefe M, Buxton AE, Chaitman B, Fromer M, et al. ACC/AHA/ESC 2006 guidelines for management of patients with ventricular arrhythmias and the prevention of sudden cardiac death: a report of the American College of Cardiology/American Heart Association Task Force and the European Society of Cardiology Committee for Practice Guidelines (Writing Committee to Develop Guidelines for Management of Patients With Ventricular Arrhythmias and the Prevention of Sudden Cardiac Death). J Am Coll Cardiol. 2006;48:e247-346.

22. Rickenbacher PR, Trindade PT, Haywood GA, Vagelos RH, Schroeder JS, Willson K, et al. Transplant candidates with severe left ventricular dysfunction managed with medical treatment: characteristics and survival. J Am Coll Cardiol. 1996;27:1192-7.

23. Butler J, Khadim G, Paul KM, Davis SF, Kronenberg MW, Chomsky DB, et al. Selection of patients for heart transplantation in the current era of heart failure therapy. J Am Coll Cardiol. 2004;43: 787-93.

\section{Discussion}

Dr Abbas Ardehali (Pacific Palisades, Calif). First, I want to compliment Ms Hoercher for an excellent presentation, and I also want to thank the authors for forwarding the manuscript to me several days in advance of this meeting.
This is a timely study that investigates the outcome of 100 status 2 patients who are removed from the transplant list because of medical improvement. The strength of this article is the long-term follow-up for 10 years. There were 3 major findings. First, the risk of return of heart failure or sudden cardiac death was about $3 \%$ to $5 \%$ per year. Second, survival of this cohort was $93 \%$ at 1 year but decreased precipitously at 5 years to $63 \%$ and at 10 years to $35 \%$. Third, when compared with a contemporaneous cohort of status 2 patients who underwent transplantation, the early survival of the delisted patients was better, but the survival curves crossed at 18 months. The status 2 patients who underwent transplantation had a better survival at 5 and 10 years.

This report contains some good news and some bad news. The good news is that the highly selected patients who were functionally improved can be removed from the waiting list safely, and for the most part, they do okay in the short term. The bad news is that most of these patients do poorly in the long term and can still benefit from heart transplantation, which brings me to 3 questions.

First, given these findings, how have you modified your approach to delisting patients, what are your protocols for monitoring the delisted patients, and at what frequency and at which center are they delisted?

Ms Hoercher. First, I would like to say that we are listing far fewer patients now than even 10 years ago. This is indeed a reflection of the expanded options available both medically and surgically. Based on these findings, we monitor patients who are listed much more closely and restage them every 6 months. For patients who are listed as status 2 and do show signs of medical improvement, we initially change them to status 7 before removing them from the list completely. This encourages them to return to see us every 3 to 6 months, at which time we repeat their metabolic stress tests, right heart catheterizations, echocardiographic analyses, and laboratory work-ups. Therefore, I would say that the findings of this study had a major effect on the way we care for this cohort of patients.

De Ardehali. So all the inactivated patients are brought back to Cleveland Clinic.

Ms Hoercher. That is correct. One of the key findings was the loss of follow-up for patients we removed over the past 20 years. We believe that if they had been followed by a heart failure specialist using evidence-based guidelines, this could have made a big difference in survival. Of course, the sobering finding of the high prevalence of sudden cardiac death in this group, coupled with such a low ICD use rate, has changed our practice in this area as well. All patients who meet the guidelines, whether they are delisted for medical improvement or status 2 patients waiting at home, receive ICDs. In addition, many are now having ICDs combined with cardiac resynchronization therapy.

Dr Ardehali. So your recommendation is to bring the patients back to the transplantation center, have them followed by the heart failure specialist at the transplantation center, and treat them according to the guidelines of the transplantation center.

Ms Hoercher. That is correct.

Dr Ardehali. Second, several studies have shown that the survival of status 2 patients undergoing heart transplantation is similar to that of those remaining on the waiting list, at least for the short term, maybe 1 to 3 years. As a result, some authorities in the heart transplantation community have suggested that it is time for 
a prospective randomized study comparing heart transplantation with optimized medical therapy in status 2 patients. Given your findings, do you think such a study is rational, or do you think we should just look at the Scientific Registry of Transplant Recipients database, maybe at 5 or 10 years out?

Ms Hoercher. I do not think we should be looking at data from the Scientific Registry of Transplant Recipients at 5 and 10 years unless the data collected become much more robust. For example, we do not know whether patients who are listed as status 2 in the Scientific Registry of Transplant Recipients database have ICDs, nor do we know their medical therapy, and therefore I do not think that these data would answer the question of transplantation versus medical therapy.

As far as the other studies you reference, I think we need to see what their results look like in 5 years before calling for a randomized trial.

Dr Ardehali. Finally, as you know, the thoracic organ committee of UNOS is now considering a new heart allocation system, a system that incorporates the wait list mortality versus the posttransplantation 1-year survival, which is very similar to the lung allocation score. Given the findings of the study, is arbitrary 1-year survival, which has been the benchmark for the lung allocation score and continues to be the foundation for the allocation system now, valid? Is it rational, or should we be looking at the 5-year survival of heart transplant recipients?

Again, congratulations on an important study and a good presentation.

Ms Hoercher. Thank you. Arbitrary 1-year transplantation survival is not a rational criterion when making a decision regarding heart allocation for transplantation. A better guide would be an ability to determine the difference between expected outcomes with and without transplantation. I think that once again, you need to balance the risks and benefits. Certainly, looking at 1-year survival is not enough; we need to look at 5-year survival as well. But I also think that we are so focused on survival in this country that we often forget to consider quality of life. All of us see our patients alive at 18 to 20 years after transplantation, but I see my patients missing lower extremities, receiving chronic dialysis, and battling cancer, to name just a few posttransplantation morbidities. Survival alone is not enough, which is why I think you need to defer transplantation for your stable status 2 patients as long as possible.

Dr Joseph Cleveland (Denver, Colo). That was a very nice presentation, and as always, data from Cleveland Clinic have helped guide a lot of things.

I have 2 questions. First, do you think status 2 patients are equivalent? In other words, one of the things that we wrestle with in
Colorado is what defines a status 2 patient. I would probably venture that a status 2 patient in Cleveland might look different than a status 2 patient in Denver, who might look different than a status 2 patient in Los Angeles. Some of it has to do with how quickly organs are offered, for example.

Second, what do you think the effect of ventricular assist device therapy might play in this, particularly with the more recent encouraging reports with destination therapy. Could this then again be, if you will, with newer-generation devices, selected patients now having survival at 3 and 5 years of perhaps $70 \%$ in centers and other places these patients can go, because I think the sobering part of your presentation is what happens to these patients long term. I would agree that having them followed in a center of heart failure transplantation excellence is part of it and that this might also be a place where destination therapy might play a role. I would be curious to hear your thoughts.

Ms Hoercher. I agree with you that a status 2 patient at Cleveland Clinic might not be the same as a status 2 patient elsewhere. That is why UNOS needs to start collecting data on medical therapy, whether patients have CRT, and whether they have ICDs. I also think that our patients who were delisted for medical improvement might have been a sicker group than patients elsewhere.

Your second question was about the role of destination therapy. I do not believe that there is a role for mechanical support in status 2 patients. Although there is increasing evidence for left ventricular assist devices earlier in the disease course and before the development of end-organ failure, at this time, patients who require inotropic support appear to derive the greatest benefit. It remains to be seen whether those less severely ill patients not receiving inotropic support, the status 2 patients, would gain a survival benefit from left ventricular assist device therapy over that of optimal medical therapy.

Dr John Benfield (Los Angeles, Calif). This is a very important and thought-provoking paper. Listing, delisting, and selection of patients for transplantation is an awesome responsibility, and we must acknowledge that we are not always right. What are your thoughts about the priority on the transplant list that should be afforded to or given to delisted patients whose status changes such that they then again become candidates for transplantation?

Ms Hoercher. That is an excellent question. As a result of this study, I am wondering whether UNOS should split status 2 into $2 \mathrm{a}$ and $2 \mathrm{~b}$. Then instead of delisting patients, they could be listed as $2 b$, recognizing that such patients would not undergo transplantation for a long time. Again, a key finding of this study is the importance of close monitoring of these patients. By keeping a patient on the UNOS list, both the patient and the transplantation center would likely be more compliant with follow-up. 